The potential of artificial aging for modelling of natural aging processes of ballpoint ink

Céline Weyermann ${ }^{1,2}$, Bernhard Spengler ${ }^{1 *}$

1 Institute of Inorganic and Analytical Chemistry

Justus Liebig University Giessen

Schuberstr.60, Bldg. 16

D-35392 Giessen

Germany

Bernhard.spengler@anorg.chemie.uni-giessen.de

2 Institut de Police Scientifique

Faculty of Law and Criminal Sciences

Lausanne University

Batochime Building

CH-1015 Lausanne

Switzerland 


\title{
The potential of artificial aging for modelling of natural aging processes of ballpoint ink
}

\begin{abstract}
Artificial aging has been used to reproduce natural aging processes in an accelerated pace. Questioned documents were exposed to light or high temperature in a well-defined manner in order to simulate an increased age. This may be used to study the aging processes or to date documents by reproducing their aging curve. Ink was studied especially because it is deposited on the paper when a document, such as a contract, is produced. Once on the paper, aging processes start through degradation of dyes, solvents drying and resins polymerisation. Modelling of dye's and solvent's aging was attempted. These processes, however, follow complex pathways, influenced by many factors which can be classified as three major groups: ink composition, paper type and storage conditions. The influence of these factors is such that different aging states can be obtained for an identical point in time. Storage conditions in particular are difficult to simulate, as they are dependent on environmental conditions (e.g. intensity and dose of light, temperature, air flow, humidity) and cannot be controlled in the natural aging of questioned documents. The problem therefore lies more in the variety of different conditions a questioned document might be exposed to during its natural aging, rather than in the simulation of such conditions in the laboratory.

Nevertheless, a precise modelling of natural aging curves based on artificial aging curves is obtained when performed on the same paper and ink. A standard model for aging processes of ink on paper is therefore presented that is based on a fit of aging curves to a power law of solvent concentrations as a function of time. A mathematical transformation of artificial aging curves into modelled natural aging curves results in excellent overlap with data from real natural aging processes.
\end{abstract}

Keywords: artificial aging, accelerated aging, heat, light, ballpoint, inks, dyes, solvents 


\section{Introduction}

Inks start to age once deposited on the paper surface. Upon aging, the ink stroke dries through solvent loss, fades through dye degradation and hardens through resin polymerisation. Document examiners have been highly interested to study these phenomena, because the possibility of dating documents by age determination would greatly help in the investigation of backdating frauds [Brunelle and Cantu, 1987; Stewart and Guertin, 1991; Brunelle and Lee, 1992; Aginsky, 1993; Cantu, 1995; Cantu, 1996].

The main problem arising in the attempt of determining the age of an ink is the dependence of aging kinetics on many factors generally unavailable to the investigator, such as the storage conditions of the questioned document, the type of paper substrate and the initial composition of the ink [Weyermann, 2005]. For these reasons it has been long considered that the only reliable way of dating a document was to compare two ink entries from the same pen on the same paper and stored under the same conditions (e.g. a diary or notebook) in order to determine which one was older [Cantu and Prough, 1987]. Considering that in all other cases a dating is difficult or even impossible, Cantu [1988] first proposed a dating method based on artificial aging, a process in which the ink stroke is exposed to conditions (such as light, heat, humidity) accelerating the normal aging process. It is assumed that these procedures can result in an aging curve when an ink entry is analysed before and after being artificially aged. Accelerated aging was first addressed in the literature, due to concerns raised by the court about the possibility of manufacturing artificially aged documents to make them look older than they are [Osborn, 1910; Stewart, 1982; Cantu, 1988]. Later the utilisation of this approach has been widely studied and discussed for the purpose of dating questioned documents [Brunelle, 1992; Lyter, 1994; Aginsky, 1996; Stewart and Fortunato, 1996; Aginsky, 1998; Brunelle and Speckin, 1998; Grim et al., 2002; Weyermann et al., 2006].

The above mentioned literature highlights strong disagreements within the scientific community about the usefulness of artificial aging. While Aginksy [1994, 1996] and Brunelle [1995] routinely used dating methods based on artificial aging in caseworks, Lyter [1994] demonstrated "the unreliability and possible misleading of this technique”. Moreover Stewart and Fortunato [1996] “requested more data regarding the number of inks tested, the reasoning for the temperature, humidity and time choices as well as the limitations of the conclusion" before routine utilisation of the accelerated aging technique and stated that "if a technique can be shown to be scientifically sound then the next logical step would be the conduct of independent validation studies at different laboratories". Margot et al. [1995] and Aginsky [1996] also agreed on the fact that "there is 
a serious need for outside proficiency testing of current ink dating methods”. However until today, no report of inter-laboratory validation was officially published and the questions stay open [Weyermann et al., 2007 c].

It is now widely accepted that the dating methods based on artificial aging and sequential extraction of $\underline{\mathbf{d y e s}}$, proved to be unreliable [Hicks Champod et al., 1995; Aginsky, 1998; Andermann and Neri, 1998; Jahns, 2004] after having been applied in several forensic case studies [Brunelle, 1998]. However methods based on artificial aging and sequential extraction of solvents are still routinely used by several laboratories in the USA and Europe [Aginsky, 1998; Bügler, 2005] without having been submitted to proper validation and proficiency testing.

Therefore the controversy on the subject of document dating and artificial aging is still going on and the document examiners community could strongly benefit from further research and thoughts about the subject of artificial aging of inks on documents. For example, the adequacy of light or heat to mimic natural aging of inks has not yet been clearly demonstrated. Heating at $100^{\circ} \mathrm{C}$ was first proposed by Cantu [1988], however Aginsky recommended the heating of the ink samples at moderate temperature $\left(60-80^{\circ} \mathrm{C}\right)$ in order to avoid denaturing of the sample [Aginksy, 1994]. UV light was also proposed to accelerate the fading of dyes [Grim et al., 2002; Weyermann et al., 2006]. The aim of this study is to evaluate the potential of artificial aging to model natural aging of ballpoint inks in order to point out the prospects and limitations of such models for the dating of questioned documents.

\section{Methods and Materials}

\subsection{Materials}

Solvents (deionised water, ethanol, acetone, dichloromethane) were purchased from Merck (Darmstadt, Germany). Reference substances used were the pure dye BV4 (basic violet 4) and the pure solvents E (ethoxyethoxyethanol) and D (dipropylene glycol) purchased from Sigma-Aldrich (Steinheim, Germany) and P (phenoxyethanol) purchased from Riedel-de-Haën (Seelze, Germany). Extraction was made in $50 \mu$ mirco glass insert, held in $1.5 \mathrm{ml}$ short amber threaded glass vials (VWR, Darmstadt, Germany) with 1,3 - Benzodioxole methanol as internal standard (Sigma-Aldrich, Steinheim, Germany). The flasks were locked with screw silicone caps coated with PTFE. A standard $10 \mu \mathrm{l}$ Hamilton syringe (Bonduz, Switzerland) was used for the injection into the GC. Blue BIC $^{\circledR}\left(\right.$ Cristal $^{\mathrm{TM}}$ medium blue, France) and blue Parker ${ }^{\circledR}$ ballpoint entries (medium blue, 
England) were made on a multifunction bright-white, wood and chlorine free paper from Igepa Plus $\left(80 \mathrm{~g} / \mathrm{m}^{2}\right.$, DINA4, nr. 806 A 80, Reinbeck, Germany).

\subsection{Aging treatments}

\subsubsection{Natural Aging}

Two batches of ballpoint ink entries were drawn every month on paper with the help of a ruler with a BIC ${ }^{\circledR}$ and a Parker blue ballpoint pen during three years. Entries were about $0.5 \mathrm{~mm}$ wide and $50 \mathrm{~mm}$ long. Fresh ballpoint pen entries were held in the laboratory (at constant temperature), while older strokes (older than a month) were kept in an office (no air conditioning). In the office, one batch was stored in darkness in a drawer and the other was exposed to daylight by being attached to an outside window facing north-west. Both the reference and the sample were kept in the same room which was located in the ground floor. The window was an iplus neutral R (Interpane Gmbh \& Co) with two float glass panels (the inside panel was coated). $76 \%$ of the incident light, but only $13 \%$ of the UV between 320 to $400 \mathrm{~nm}$ were transmitted through the double panes. The heat transmission coefficient has a value of $1.2 \mathrm{~W} / \mathrm{m}^{2} \mathrm{~K}$. The photon flux through the window per unit of surface was measured with two silicon photodiode from United Detector Technology, the first one (PIN-10DFP) producing a flat spectral response of $1.5 \mathrm{~A} / \mathrm{W}$ between 400 to $1000 \mathrm{~nm}$, and the second one (UDT-UV100, UV enhanced) offering spectral response between 200 to $1000 \mathrm{~nm}$. The first of these detectors was used to measure visible light. The second detector was used to measure UV light with a solar blind filter SB-300-F from Laser Components $\mathrm{GmbH}$ used to cut off the visible light (transmission of $40 \%$ between 220 and $360 \mathrm{~nm}$ ). The relative numbers of photons per surface area and time unit were continuously measured in volts after being amplified by a factor of $10^{4} \mathrm{~V} / \mathrm{A}$ for the visible range, and of $10^{6} \mathrm{~V} / \mathrm{A}$ for the UV range, and then recorded with a high performance multifunctional PCI Adapter (PCI-1002L) with 32 SE/16D Analog Inputs, 12-bit ADC, 110 kHz, 16 DI, 16 DO and a timer from IPC2U (Industrial Personal Computer 2U GmbH, Langenhagen, Germany). The same card was used to record the temperature and humidity measured with two universal thermohygrometer modules UTH $100\left(\right.$ ELV $^{\circledR}$ Elektronik AG, Leer, Germany). The data were then processed using a program written by Alfons Hester (Analytical Chemistry, JLU Giessen, Germany).

\subsubsection{Artificial Aging}

Parker ballpoint strokes on paper were stored in an oven at $60^{\circ} \mathrm{C}$ (for solvent drying), while $\mathrm{BIC}^{\circledR}$ ballpoint strokes on paper were stored in an oven at $100^{\circ} \mathrm{C}$ or exposed to xenon light during 50 hours (for dye fading). A 
reference sample was held in a dark box. LDI measurements were carried out every 5 hours. A Heraeus oven $(220 \mathrm{~V}, 52 \mathrm{~A}, 50 \mathrm{~Hz}, 1.14 \mathrm{~kW})$ at a temperature of $100^{\circ} \mathrm{C}$ was used to heat the samples. To expose the sample to light, a xenon high-pressure lamp (Leitz GmbH, Wetzlar, Germany, 220/240 V, 50 Hz, XBO/CSX 450 W) was chosen, because the xenon lamp irradiance covers the entire wavelength range from $250 \mathrm{~nm}$ to more than 1000 $\mathrm{nm}$ with high fluence. Samples were positioned $17 \mathrm{~cm}$ away from the light source.

\subsection{Analysis}

\subsubsection{LDI-TOF-MS (dye degradation analysis)}

Mass analyses of the chemical degradation of the pure dyes and of ink entries on paper were conducted on a home-built Laser Desorption Ionization (LDI) Reflector Time-of-flight (TOF) mass spectrometer (MS) [Chaurand et al., 1999]. Desorption / ionisation was performed with a pulsed nitrogen laser (337nm, 3ns, 20 $\mu \mathrm{m}$ focus diameter). Delayed extraction was employed in the positive ion mode (allowing the analysis of cationic dyes). Mass spectra were recorded by averaging 100 individual laser pulse spectra and the typical mass resolving power $\mathrm{M} / \Delta \mathrm{M}$ was between 3000 and 6000 . The laser irradiance was regulated with an attenuator between the laser and the sample, allowing to find the operative threshold irradiance at which a sample was desorbed and ionised adequately [Weyermann et al., 2006]. Degradation measurements were averaged from 4 to 6 summed spectra acquired along 2-3 strokes for each point of a given aging curve. To perform analysis on the paper, small pieces of $5 \times 8 \mathrm{~mm}$ with 2-3 strokes running on the long side, were cut, glued with a carbon tape to a metallic sample holder and introduced into the MS. Paper blanks were also performed to ensure that no signal from the substrate was interfering.

\subsubsection{GC/MS (solvent drying analysis)}

Analyses of the solvents were made on a Gas Chromatograph / Mass Spectrometer (GC/MS) MAT 4500 from Finnigan MAT GmbH, Bremen (now Thermo Fisher Scientific GmbH, Bremen). The instrument was equipped with the data acquisition software MASPEC Data System (MSS - Mass Spectrometry Services Ldt., Manchester, England). Separation was carried out on a CP-Sil 8 CB low bleed / MS capillary column from Varian (Chrompack, Middleburg, Netherlands). The column was $60 \mathrm{~m}$ long and had an internal diameter of 0.25 $\mathrm{mm}$ and film thickness of $0.25 \mu \mathrm{m}$. The chromatographic elution was temperature programmed as follows: isothermal at $50^{\circ} \mathrm{C}$ for $6 \mathrm{~min}$, then from 50 to $300^{\circ} \mathrm{C}$ at a rate of $10^{\circ} \mathrm{C} / \mathrm{min}$, and finally istothermal at $300^{\circ} \mathrm{C}$ for 5 min. The carrier gas was helium (Messer Griesheim GmbH, Frankfurt, Germany) with a constant flow of 
$\sim 3 \mathrm{ml} / \mathrm{min}$ (at $30 \mathrm{psi}$ ). For the chromatographic separation, a solvent delay of $300 \mathrm{~s}$ was chosen. To improve sensitivity, the sample was injected in the splitless mode and the injector temperature was maintained at $200^{\circ} \mathrm{C}$, which was sufficient to volatise all the substances of interest. The interface temperature was set to $250^{\circ} \mathrm{C}$ to avoid recondensation. The MS part of the GC/MS was a highly sensitive quadrupole instrument with a mass-tocharge range up to $1000 \mathrm{u}$. Ions were formed by electron impact (EI), with a fixed electron energy of $80 \mathrm{eV}$. The temperature of the ionisation block was kept at $120^{\circ} \mathrm{C}$. For qualitative analysis, the instrument was used in the SCAN or TIC (Total Ion Current monitoring) mode. Masses were scanned in the quadrupole from m/z 33 to 400 $\mathrm{u}$ at a sweep time of $0.95 \mathrm{~s}$. To ensure better quantitative accuracy, the SIM (Selected Ion Monitoring) mode was employed, due to its higher sensitivity. This allowed lower quantities of solvents to be detected and quantified than in the TIC mode. For the purpose of the intended analysis, 15 particular ions were selected and monitored, corresponding to the masses: $45,59,65,72,75,77,89,93,94,103,104,135,138,152$ and $182 \mathrm{u}$. These ion signals correspond to the four solvents found in the chosen ballpoint pen and the internal standard. The identification of the eluting substances was carried out in earlier studies [Weyermann et al., 2007b]. Ballpoint pen entries of about $1 \mathrm{~cm}$ were cut in $10 \times 2 \mathrm{~mm}$ rectangles from the paper sheet and placed in a small vial. The solvents were extracted during 10 minutes in an ultra-sonic bath in 10ul dichloromethane with an internal standard concentration of $0.0227 \mathrm{mg} / \mathrm{ml}$. A $2 \mu \mathrm{l}$ aliquot from the extraction mixture was then injected splitless on the GC column. Pieces of paper of identical dimensions were cut and extraction was carried out following the same procedure.

\section{Results}

\subsection{Dye Fading}

When dyes fade, they undergo a photochemical reaction that begins with the absorption of visible or ultraviolet light. Absorption of a photon by an organic molecule leads to formation of an electronically excited state that is the starting point for subsequent reaction steps. Photochemical reactions are influenced by the concentration of the reactants, the reaction medium, the temperature, the wavelength and intensity of the light [Klessinger and Michl, 1989]. Theses observations were also made for ink fading reactions [Weyermann, 2005; Weyermann et al., 2006]. The degradation of triarylmethane dyes, such as Basic Violet $3(\mathrm{BV} 3 ; \mathrm{m} / \mathrm{z}=372$ 
$\mathrm{g} / \mathrm{mol})$ and Basic Violet $4(\mathrm{BV} 4 ; \mathrm{m} / \mathrm{z}=456 \mathrm{~g} / \mathrm{mol})$, was characterised in a previous work by LDI-MS using the relative peak area of the dye [Weyermann et al., 2006], defined as

$$
R P A_{i}=\frac{A_{i}}{A_{t o t}}
$$

where $A_{i}$ is the area of the signal at $m / z=i$ and $A_{t o t}$ is the total area of all the signals (molecular ion and related degradation products) of a particular dye. With this definition it is possible to define a given $\mathrm{RPA}_{\mathrm{i}}$ for each dye of a given ballpoint ink [Weyermann et al, 2007a], which is mass invariant (i.e. value does not depend on the amount of ink sampled). The RPA values decrease when the ink ages.

\subsubsection{Natural Aging of dyes}

While some ink entries were stored in the dark during three years, other entries were exposed to daylight for periods of up to three years during the winter and summer seasons. The LDI-MS measurements from the set of entries stored in the dark were compared to the measurements of three sets of entries exposed to daylight (winter 2002, summer 2002, and summer 2004). As expected, degradation of the dyes occurred within a shorter time in the spring-summer period where daily exposure to light was longer (Figure 1). For measurements started in the summer 2002, the degradation levelled off after 100 days. Measurements started in the summer 2004 showed the strongest degradation, as levelling off occurred after 50 days. In autumn and winter, the exposure to light was shorter and degradation had not yet reached a limiting value after six months [Weyermann et al., 2006]. No degradation occurred within three years of storage in the dark, demonstrating the strong influence of light on the aging. 


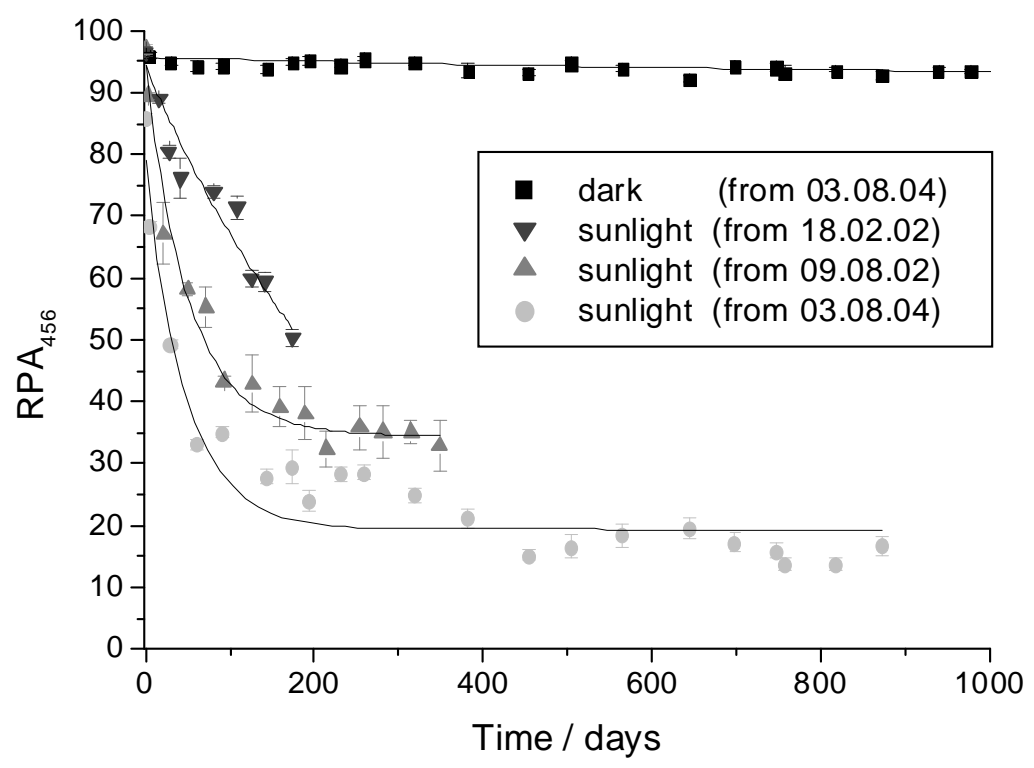

Figure 1 - Seasonal and storage condition influence on natural aging of a blue BIC ${ }^{\circledR}$ ballpoint ink containing BV4. One document was stored in a dark cupboard for about three years and showed no fading of BV4. The others were exposed to daylight in three different periods of time. In winter 2002 the aging was the least pronounced, while in summer 2004 it was the strongest.

Photodiodes measuring visible-light and UV-light were fixed to the window for permanent measurements of the incident light impinging on the ink entries held against the window. The power of the incident light per surface area was determined with two photodiodes giving readings in volts. These values are readily converted as follows to obtain values for the irradiance in watt per $\mathrm{m}^{2}$ :

$$
\frac{\text { photodiode reading }[V]}{\text { amplification }[V / A] * \text { responsivity }[A / W] * \text { area }\left[\mathrm{m}^{2}\right]}=\text { power per surface area } \quad\left[\mathrm{W} / \mathrm{m}^{2}\right]
$$

It thus was possible to measure the power of the incident light per unit surface area as a function of time (Figure 2). In summer, the evening sun reaching the window caused an increase in irradiance toward the end of the day, which was not observed when clouds masked the sun. During spring and winter, the days were shorter and the amount of light measured was lower, particularly in winter as direct sunshine reached the window only after 5 p.m.. The weather was often foggy and rainy during this season, while summer days were often sunny. Therefore, very different number of photons reached the window depending on season and weather. UV light irradiance coming through the window was about 100 times lower than that of visible light (because UV 
transmission was reduced by the window glass). The obtained values supported the hypothesis that aging rate was dependent on the amount of light reaching the windows, but a direct correlation was not possible.

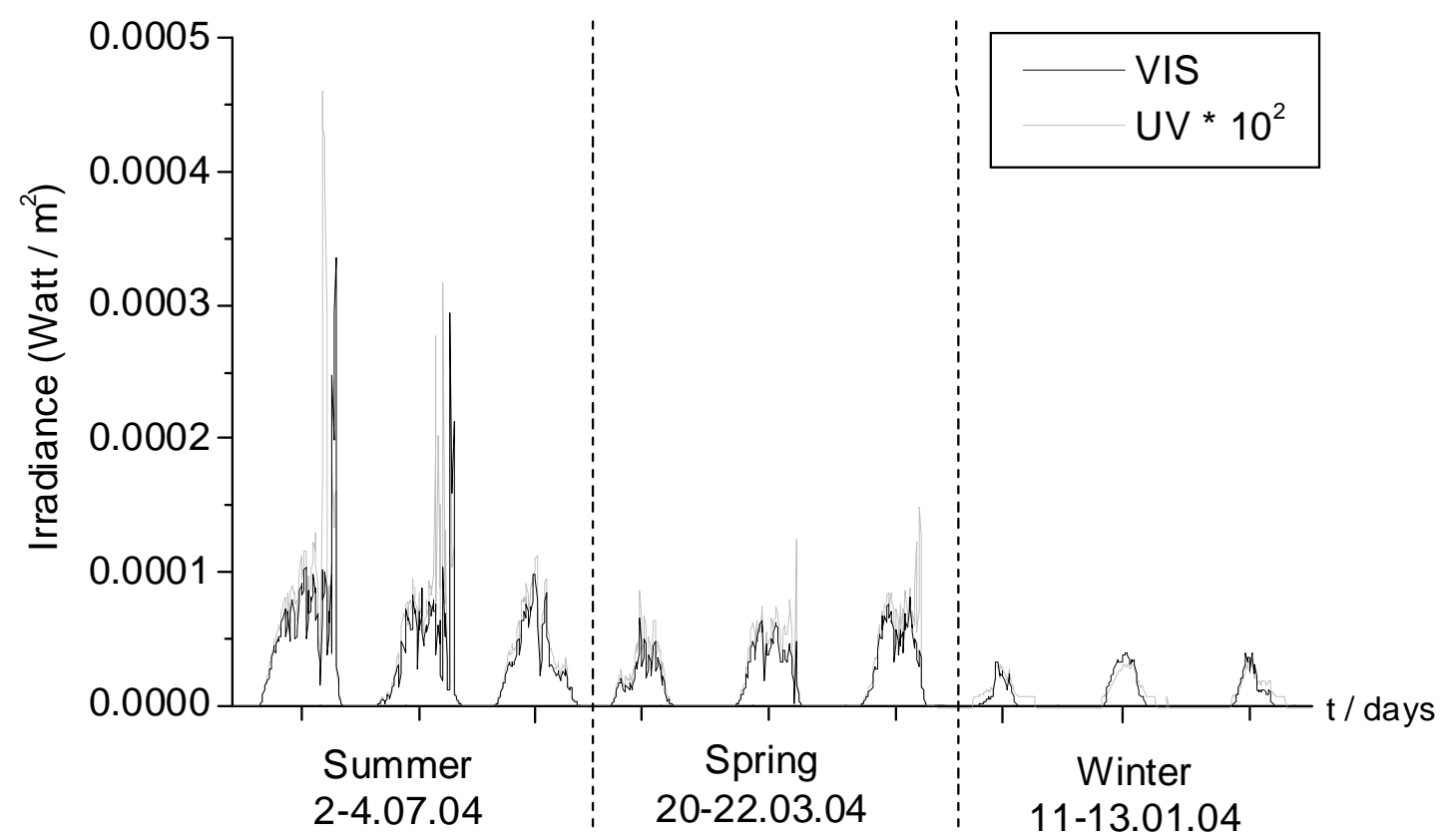

Figure 2 - Comparison of daylight irradiance $\left[\mathrm{W} / \mathrm{m}^{2}\right]$ coming through the window during three days in the summer, spring and winter 2004. The irradiance of the UV light was multiplied by a factor of 100 for better visualisation. In summer, the energy increased during the evening hours as a result of direct sunshine reaching the window. On the $4^{\text {th }}$ of July, clouds concealed the sun. Days are considerably shorter in spring and winter, hence the amount of light reaching the window during the day was very low.

During several summer days, temperature and humidity were recorded at the window and in the cabinet holding the ink strokes. It was observed that these parameters were rather constant in the cabinet, since almost no air flow occurred in it. At the window they strongly varied. On sunny days, the temperature increased during the day while the humidity decreased. On rainy days, the humidity reached high values. Even larger variations could be observed between summer and winter. Light, temperature and humidity strongly influenced these natural aging experiments and would therefore also influence the aging of a questioned document in real caseworks.

Additionally, previous work [Weyermann, 2005] demonstrated the strong influence of the ink composition on the aging kinetics. 


\subsubsection{Artificial Aging of dyes}

Artificial aging was carried out during 50 hours using an oven at $100^{\circ} \mathrm{C}$ or a xenon lamp. A standard was kept in a dark box at ambient temperature during the same period of time for comparison. The aging curve of the standard was flat: no change was recorded after 50 hours (Figure 3). The corresponding curve for the strokes exposed to a temperature of $100^{\circ} \mathrm{C}$ showed a slight degradation of the dye BV4, while the curve for strokes exposed to light of the xenon lamp exhibited a steep decrease of the signal of BV4: the RPA 456 value attained $30 \%$ after 50 hours. No levelling off of the degradation process was observed after a time exposure of 50 hours. The xenon lamp also caused a slight increase in temperature from room temperature $\left(22^{\circ} \mathrm{C}\right)$ to $30^{\circ} \mathrm{C}$.

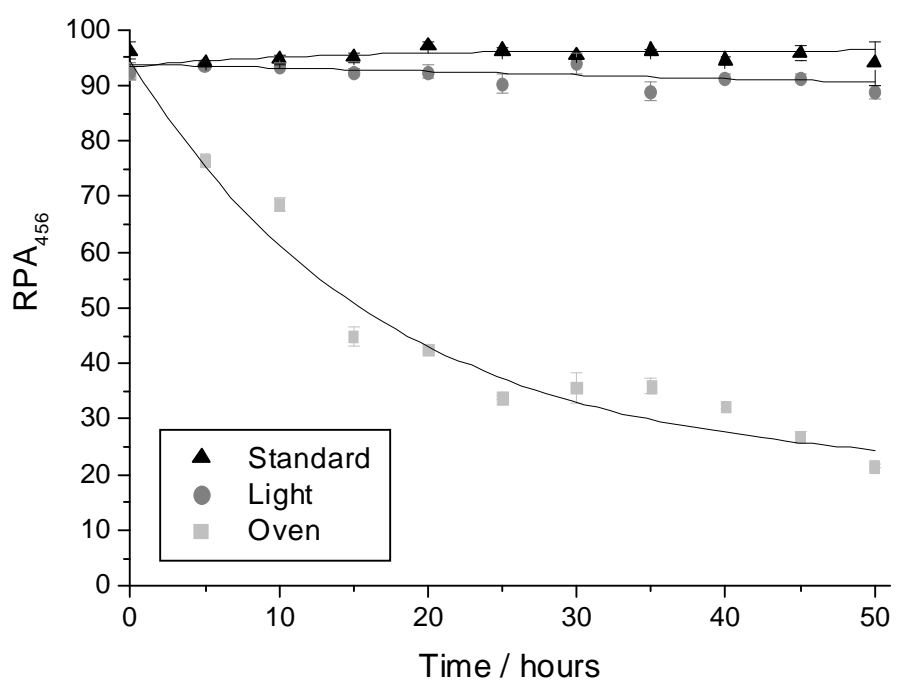

Figure 3 - $\quad$ Artificial aging of Basic Violet 4 contained in ink entries from a BIC $^{\circledR}$ ballpoint pen, induced by the following treatments over a time of 50 hours: (I) storage in the dark at room temperature, (II) storage in an oven $100^{\circ} \mathrm{C}$, and (III) exposure to a high- pressure xenon lamp. The aging curves show that heat caused slight degradation of Basic Violet 4, while light had a strong effect already observed after a few hours exposure.

\subsubsection{Aging Modelling for dyes}

Considering how dependent the aging results were on the storage conditions, it was evident that a simulation or modelling of natural aging (NA) behaviour by artificial aging (AA) processes would not be able to match all situations. No aging was detected for samples stored in the dark; therefore modelling was attempted only between agings upon light exposure. Modelling revealed large differences between the three sets of natural aging experiments conducted in this work: 
- $\quad$ winter 2002:

- $\quad$ summer 2002:

- $\quad$ summer 2004:
50 hours of AA corresponds to about 600 days of NA

50 hours of AA corresponds to about 200 days of NA

50 hours of AA corresponds to about 80 days of NA

Moreover, the shapes of the curves for AA do not exactly match all types of curves for NA (Figure 4). For these reasons, one cannot advocate the use of artificial aging of dyes for the purposes of dating ink from a single entry in situations where the number and energy of the incident photons reaching the ink are not known.

For samples stored in the dark, the experiment should be carried out over a much longer period of time. Some experiment made on entries from 5 ballpoint pens over 14 years showed no significant degradation of the dyes they contained [Weyermann, 2005]. Natural aging of dyes occurs so slowly in the absence of light or heat that their use for the dating of documents is of a very limited degree.
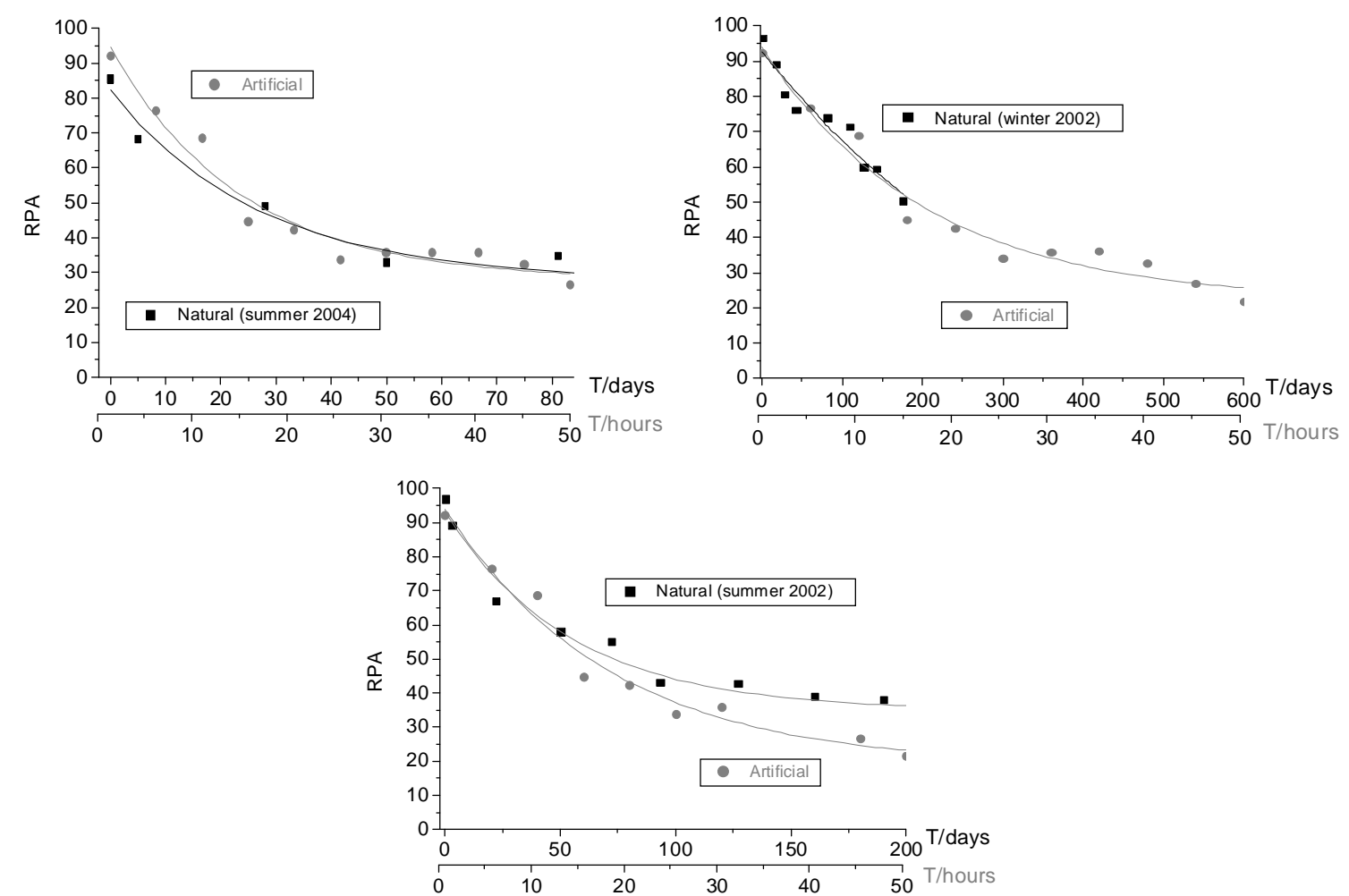

Figure 4 Attempts of modelling the natural aging (NA / days) with artificial aging curves (AA / hours). Very different results were obtained for the three NA experiments (winter 2001/02, summer 2002 and summer 2004) and, except for the winter of 2001/02, the modelling of NA by AA does not yield a perfect fit of the NA curves. 


\subsection{Solvents drying}

The objective of ballpoint pen manufacturers is to produce a fluid ink. Ink drying is a very complex phenomenon characterized by evaporation of the solvents in the ambient air and their simultaneous adsorption on and diffusion into the paper. Among other things, these processes are influenced by temperature, humidity, air flow and the adsorption/diffusion properties of the paper - solvent system [Weyermann et al., 2007b].

The drying of solvents was followed by their relative quantification in the ballpoint pen entry. The relative peak area (RPA) for any given substance $S_{i}$ was calculated as follows to minimize the error [Weyermann et al., 2007b]:

peak area of $S_{\mathrm{i}}$

$\mathrm{RPA}=$

peak area of internal standard
Eq. 2

The RPA is a measure of the quantity of solvent in the stroke relative to that of the internal standard (i.e. it is mass dependent and varies with the amount of ink sampled). RPA values decrease when the ink ages.

\subsubsection{Natural Aging of solvents}

Natural aging of ink through solvent loss was followed over a period of three years in the ink entries of a Parker ballpoint pen containing four solvents: ethoxyethoxyethanol (E), dipropylene glycol (D), phenoxyethanol (P), and phenoxyethoxyethanol (PE). In the solvent drying curves measured by GC/MS (Figure 5), three aging phases might be distinguished visually, covering the first few hours ( 0 to 3 hours), the first few days ( 3 to 48 hours), and the time beyond two weeks (> 336 hours). It is, however, obvious from the double-logarithmic representations of the same data, that solvent drying proceeds uniformly and continuously, following a common power law for the complete period of observation (see Fig. 6 and 7). Above one year the quantities still detected in the ink stroke were in the nanogram per centimeter range. 

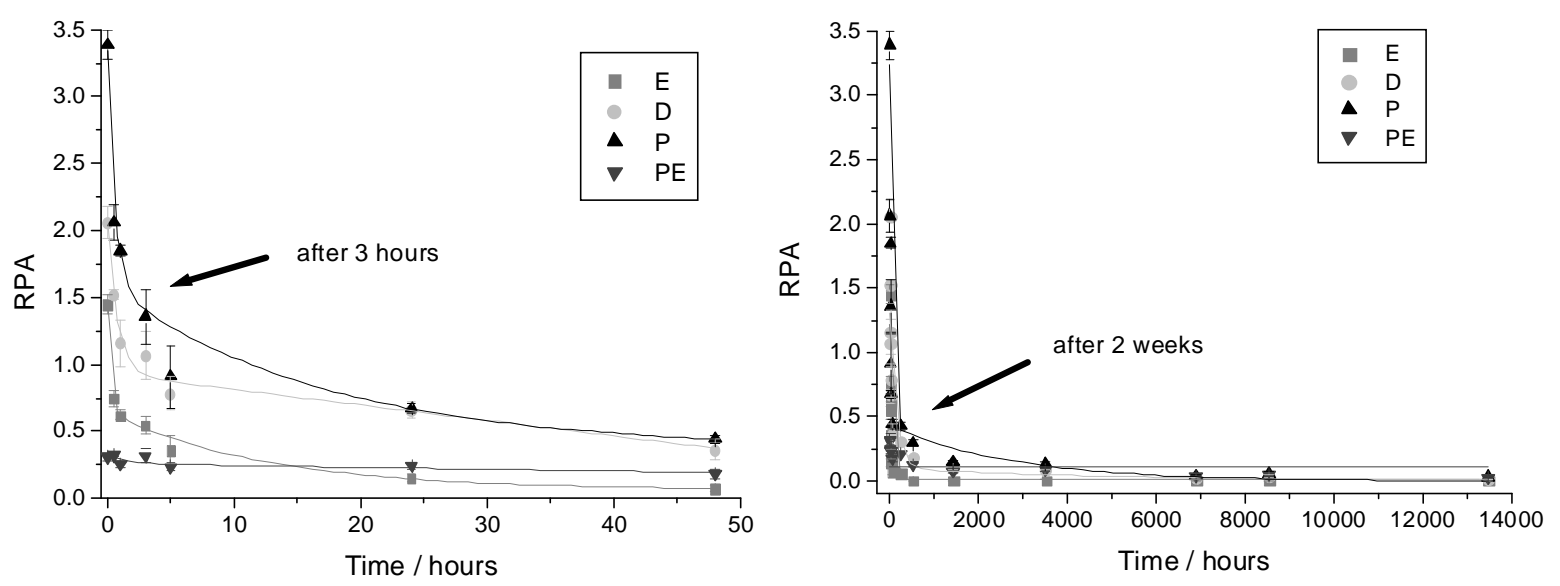

Figure 5 Drying curves obtained by GC/MS for four ballpoint solvents (E: ethoxyethoxyethanol, D: dipropylene glycol, P: phenoxyethanol, PE: phenoxyethoxyethanol) from Parker ballpoint pen entries. The Relative Peak Areas (RPA) plotted as functions of time are proportional to the solvent concentration. Drying slowed down considerably with time. Three stages can seemingly be distinguished in this linear plot of data: 0 to 3 hours, 3 to 48 hours and beyond two weeks.

The drying of the solvents $\mathrm{E}$ and $\mathrm{D}$ were compared in ink entries made by two different ballpoint pens on the same type of paper. The ink of the BIC ballpoint pen contained only these two solvents, while the Parker pen additionally contained P and PE. Surprisingly, the drying rate of E is slightly higher in the BIC strokes, while the drying of D is slightly higher in the Parker entries. Also, E was no longer detected in the BIC entries after 48 days, while small quantities of $\mathrm{E}$ were still found in the Parker ink entries after more than one year (Figure 6). Data is presented in Fig. 6 on a double logarithmic scale. Parametric functions following a power law of the general form $\mathrm{y}=\mathrm{a} \cdot \mathrm{x}^{\mathrm{b}}$ result in linear curves in a double logarithmic representation $\log (\mathrm{y})=\log (\mathrm{a})+\mathrm{b} \cdot \log (\mathrm{x})$.

Evaluation of the double logarithmic fit functions of Figure 6 led to significantly different exponents of the power law for the different solvents and inks. In the fit function

$$
R P A=a \cdot t^{b}
$$

the exponent $\mathrm{b}$ was determined from Fig. 6 for the different compounds as listed in Tab. 1. The results show that for ethoxyethoxyethanol (E), the power law is close to RPA (or solvent concentration) being proportional to $\frac{1}{\sqrt{t}}$, while for dipropyleneglycol (D) the behaviour is closer to RPA (or concentration) being proportional to $\frac{1}{\sqrt[3]{t}}$ 


\begin{tabular}{|l|c|c|}
\hline b & Parker & BIC \\
\hline Dipropylene glycol (D) & -0.36 & -0.25 \\
\hline Ethoxyethoxyethanol (E) & -0.45 & -0.65 \\
\hline
\end{tabular}

Table 1: Values of exponent $\mathrm{b}$ in the fit function RPA $=\mathrm{a} \cdot \mathrm{t}^{\mathrm{b}}$ from fig.6.

The different drying behaviour of $\mathrm{D}$ and $\mathrm{E}$ in different ink compositions could mean, that either solvent dynamics were significantly influenced by the ink composition, or that undetected variations of external factors (temperature, air flow, adjacent material) had influenced the drying process. The initial composition of the ink should therefore also be taken into account in the study of the drying of ink.
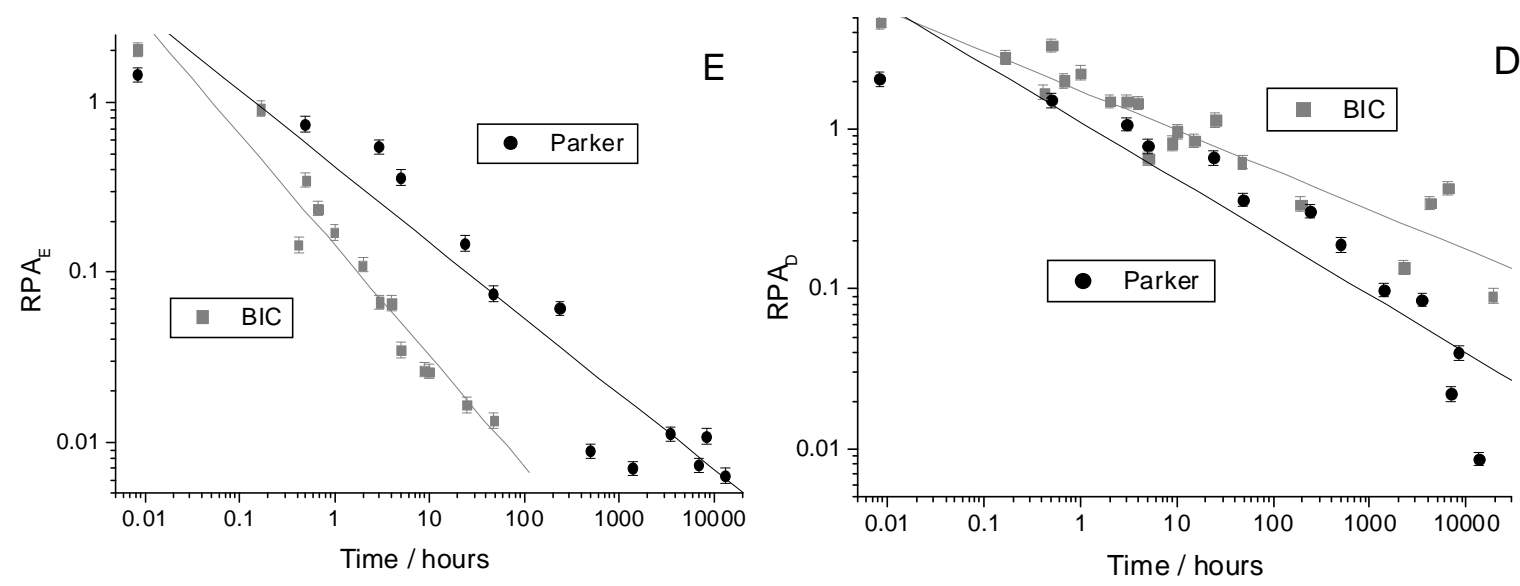

Figure 6 Comparison of the drying of E (ethoxyethoxyethanol) and D (dipropylene glycol) on paper from the ink entries of two ballpoint pens BIC and Parker by GC/MS. Logarithmic scales were used for the RPA (Relative Peak Area of solvent) and for the time scale. The drying rates obviously differ significantly between the two inks, as do the exponents $b$ of the power law.

\subsubsection{Artificial Aging of solvents}

Ink entries made with the Parker ballpoint pen were stored for 17 days in an oven at $60^{\circ} \mathrm{C}$ while performing quantitative GC/MS measurements at various times. All four solvents decreased faster at higher temperature (Figure 7). The difference is particularly important for solvents with high boiling point or viscosity. Even PE, which diminished very slowly at room temperature showed a significant decrease at $60^{\circ} \mathrm{C}$. Exponents of the power law are listed in Tab. 2. 

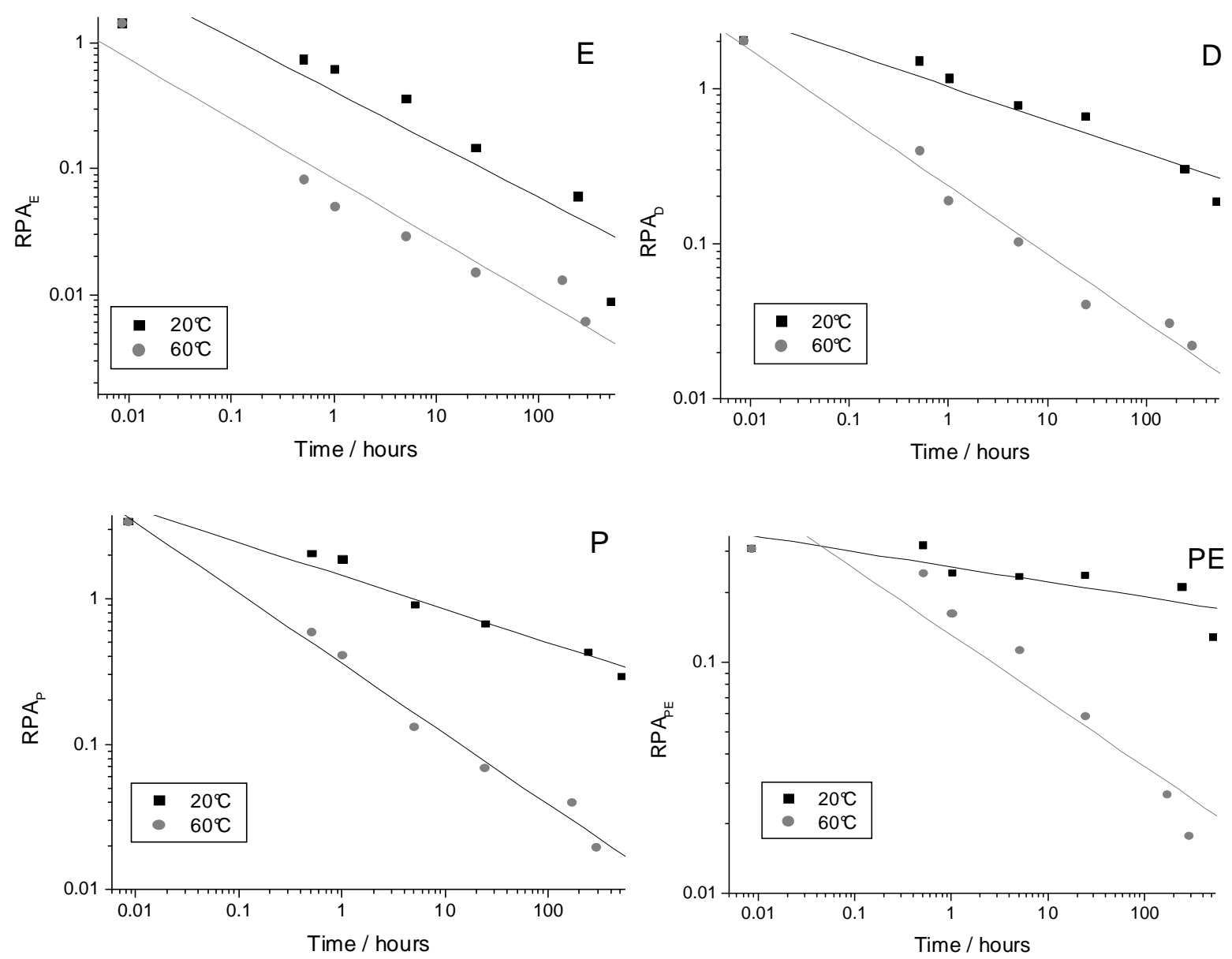

Figure 7 Solvent losses from ink entries from Parker ballpoint pen entries stored at $20^{\circ} \mathrm{C}$ and at $60^{\circ} \mathrm{C}$ over 17 days, determined by GC/MS. Logarithmic scales were used for the RPA (Relative Peak Area of solvent) and for the time scale. All four solvents decreased faster at higher temperature, accompanied by higher exponents of the power law.

\begin{tabular}{|l|c|c|}
\hline $\mathbf{b}$ & $\mathbf{2 0}^{\circ} \mathbf{C}$ & $\mathbf{6 0}^{\circ} \mathbf{C}$ \\
\hline Ethoxyethoxyethanol (E) & -0.42 & -0.47 \\
\hline Dipropylene glycol (D) & -0.21 & -0.44 \\
\hline Phenoxyethanol (P) & -0.23 & -0.48 \\
\hline Phenoxyethoxyethanol (PE) & -0.065 & -0.28 \\
\hline
\end{tabular}

Table 2: Values of exponent $\mathrm{b}$ in the fit function RPA $=\mathrm{a} \cdot \mathrm{t}^{\mathrm{b}}$ for Parker ballpoint pen entries from fig. 7. 


\subsubsection{Aging model for solvents}

An attempt was made to model natural aging (at $20^{\circ} \mathrm{C}$ ) by artificial aging (at $60^{\circ} \mathrm{C}$ ). Using the fit functions derived from Fig. 7 and data as shown in Fig. 5, coefficients a and b of the power law RPA $=a \cdot t^{b}$ were determined for solvents E, D, P and PE after natural aging and artificial aging at $60^{\circ} \mathrm{C}$, respectively (see Tab. 3).

\begin{tabular}{|l|c|c|c|c|}
\hline & $\mathbf{a}_{\text {artificial } 60^{\circ} \mathbf{C}}$ & $\mathbf{b}_{\text {artificial } 60^{\circ} \mathbf{C}}$ & $\mathbf{a}_{\text {natural }}$ & $\mathbf{b}_{\text {natural }}$ \\
\hline Ethoxyethoxyethanol (E) & 0.0831 & -0.4749 & 0.6425 & -0.5126 \\
\hline Dipropylene glycol (D) & 0.2343 & -0.4372 & 1.7095 & -0.4305 \\
\hline Phenoxyethanol (P) & 0.3587 & -0.4829 & 2.0321 & -0.3846 \\
\hline Phenoxyethoxyethanol (PE) & 0.1312 & -0.284 & 0.3573 & -0.2074 \\
\hline
\end{tabular}

Table 3: Values of factor $a$ and exponent $b$ in the fit function RPA $=a \cdot t^{b}$ for artificial aging at $60^{\circ} \mathrm{C}$ and for natural aging at $20^{\circ} \mathrm{C}$ (natural aging data are those presented in Fig. 5).

Using these coefficients, a transformation function between the time of artificial aging ( $\mathrm{t}_{\text {artificial }}$ ) and a corresponding time of natural aging ( $\left.\mathrm{t}_{\text {natural fit }}\right)$ was derived according to Equation 4.

$$
t_{\text {natural fit }}=\left(\frac{a_{\text {artificial }}}{a_{\text {natural }}}\right)^{1 / b_{\text {natural }}} \cdot t_{\text {artificial }}^{\left(\frac{b_{\text {artificial }}}{b_{\text {natural }}}\right)}
$$

The resulting correlation graphs for the different solvents are shown in Figure 8. They can be used for direct recalculation of artificial aging times into corresponding natural aging times for the investigated systems (paper, ink composition, environmental parameters).
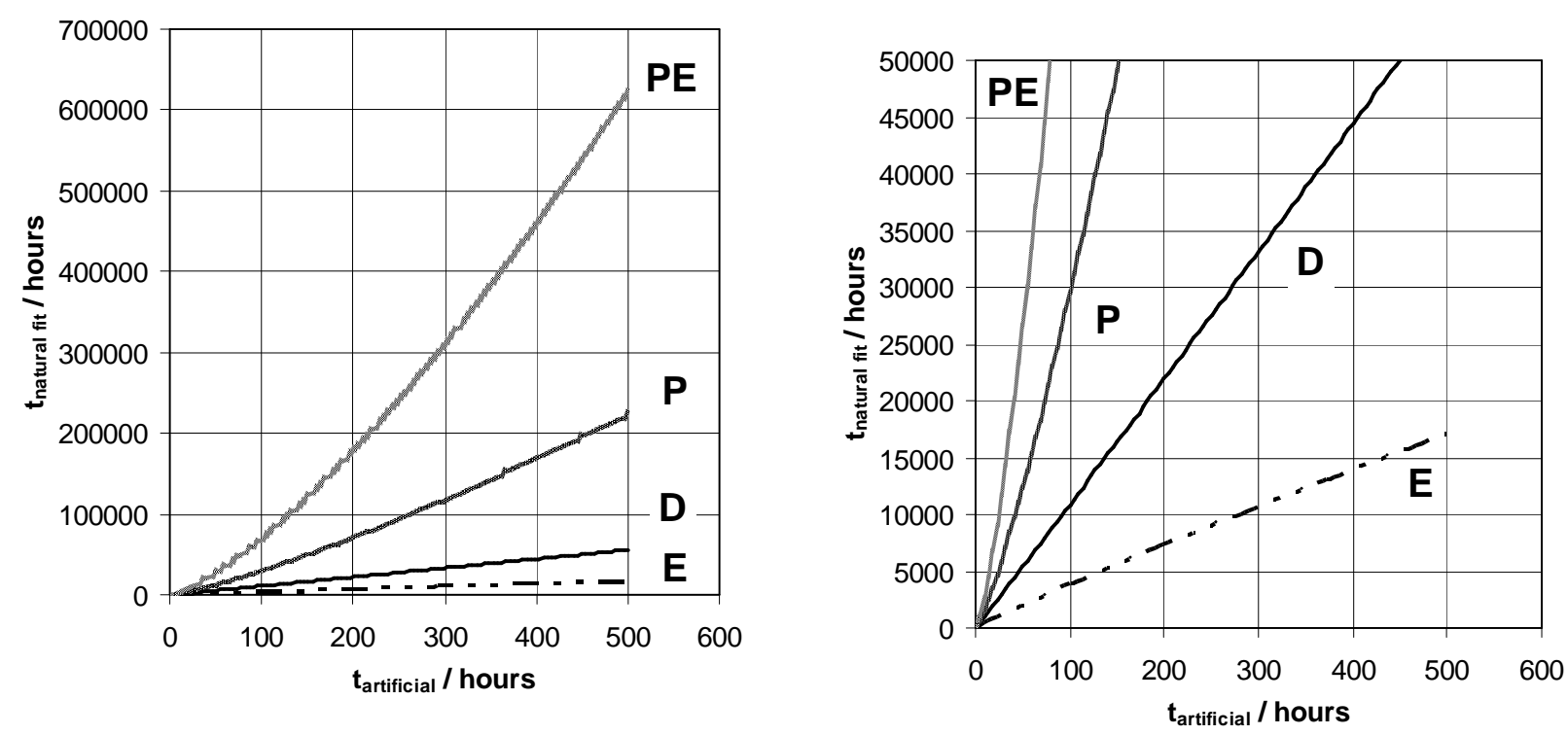
Figure 8 Correlation between natural aging times $\left(20^{\circ} \mathrm{C}\right)$ and artificial aging times $\left(60^{\circ} \mathrm{C}\right)$ as derived from data shown in Fig. 5 and 7. Two different vertical scalings are shown in the left and the right.

The following correlations, for example were obtained for the four solvents in the Parker ballpoint ink entries:

- E: $\quad 10$ hours at $60^{\circ} \mathrm{C}$ correspond to about 500 hours natural aging at $20^{\circ} \mathrm{C}$

- D: $\quad 10$ hours at $60^{\circ} \mathrm{C}$ correspond to about 1000 hours natural aging at $20^{\circ} \mathrm{C}$

- P: $\quad 10$ hours at $60^{\circ} \mathrm{C}$ correspond to about 1600 hours natural aging at $20^{\circ} \mathrm{C}$

- PE: $\quad 10$ hours at $60^{\circ} \mathrm{C}$ correspond to about 2900 hours natural aging at $20^{\circ} \mathrm{C}$

The results were unexpected, inasmuch as accelerated aging was the strongest for a solvent with a rather high boiling point $(\mathrm{P})$, and differed significantly between solvents. The artificial aging curves result in rather good power fits to the natural aging curves, but it is imperative to verify that the modelling does not change between ballpoint pens having different ink compositions. It is likely, moreover, that paper properties (especially surface and capillary structure) play a significant role in a modulation of the drying characteristics.

Using Equation 3, RPA data from artificial aging (Fig. 7) were recalculated into modelled data for natural aging conditions. To demonstrate the excellent model quality, recalculated artificial aging data and natural aging data (Fig. 5) are plotted into the same diagrams (Fig. 9).

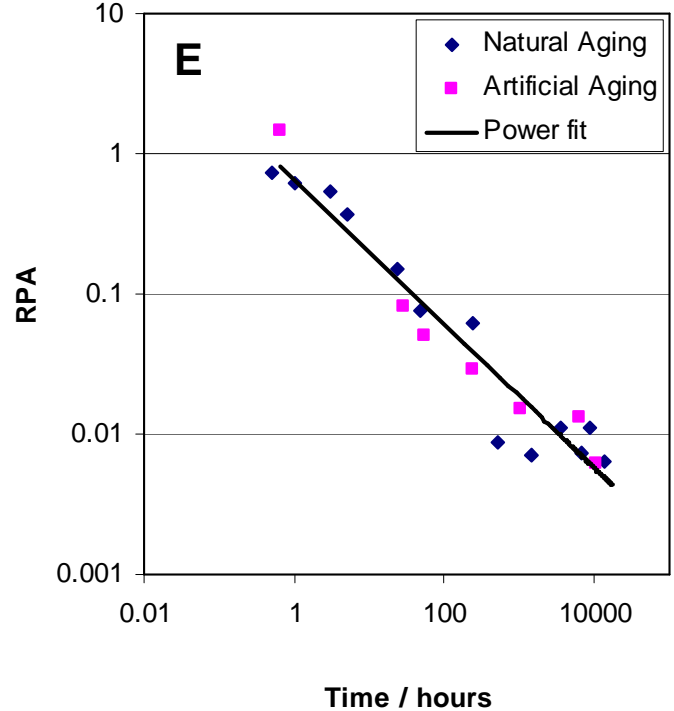

Time / hours

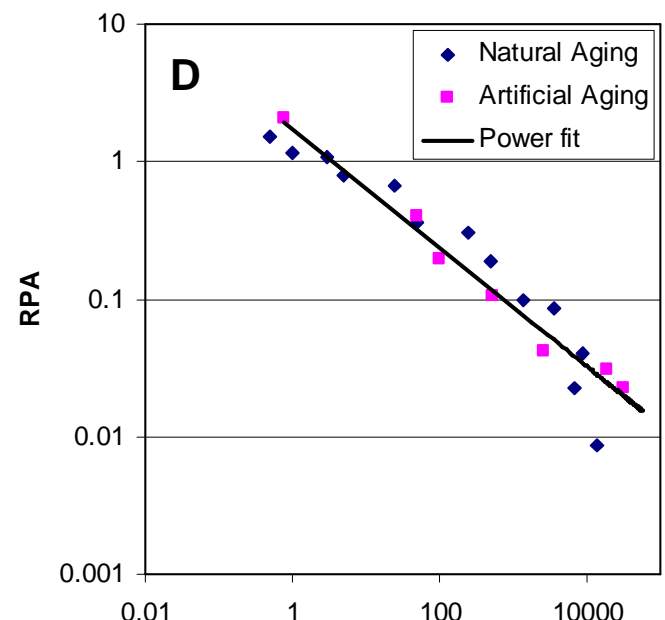

Time / hours 

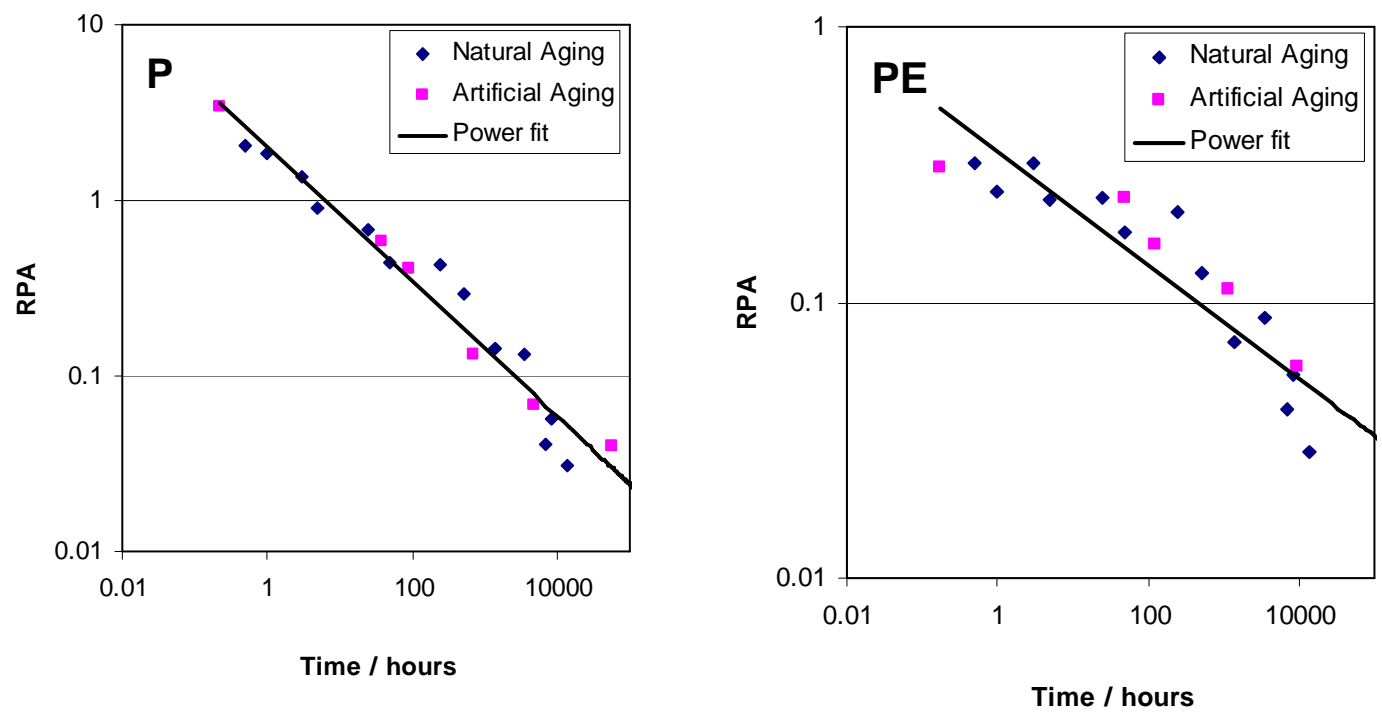

Figure 9 Attempt to model the natural aging $\left(20^{\circ} \mathrm{C}\right)$ by artificial aging $\left(60^{\circ} \mathrm{C}\right)$ curves for data as presented in Fig. 5 and 7. Artificial aging time values were recalculated from artificial aging data by transformation to natural aging time values using Equation 3.

\section{Discussion}

Dye degradation proved to be more complex than solvent drying, but both aging phenomena encounter similar problems in the attempt to model their natural aging (NA) by artificial aging (AA). This is due to the complexity of the aging processes of ballpoint inks on paper substrates [Weyermann, 2005] rather than due to the limitation of the artificial treatments.

Firstly aging is strongly influenced by ink composition. The kinetics are dependent on the type of molecules and their mixture. Each solvent or dye will age at a different pace, and for example, the additional presence of a pigment in an arylmethane dye mixture competes for the absorption of photons, and as a consequence quenches the aging. Likewise, diffusion and evaporation of solvents are dependent on their mixture.

The type of substrate has also a non-negligible influence. Paper weight, thickness, porosity, fibres alignment, and coating all play a significant role in the aging processes, which are complicated by paper-ink matrix interactions. 
Finally, aging is most strongly influenced by storage conditions. Aging follows different pathways if it is provoked by light or heat. The kinetics will also dependent on the amount of light or the temperature to which the documents are exposed. In fact, storage conditions are different from case to case, and even within a case. It is very difficult to reconstruct the amount of light and the temperatures to which documents were exposed, because they generally vary quite much along the days or years (sunny or cloudy, warm or cold weather duration, number of hours a lamp is turned on per day, position of the document in the office, adjacent documents, amount of ink of the paper, movement of the document, etc.). For example, the ink entry density on the document also plays a decisive role in the drying of the ink. A questioned document will most probably carry a text with curved line from an alphabet. For example in the letter "o", the solvents will diffuse to some extent away from the letter and partly to inside the ring. This might increase the quantities of solvents found in such a letter compared to a straight line of the same length (Figure 10).

a)

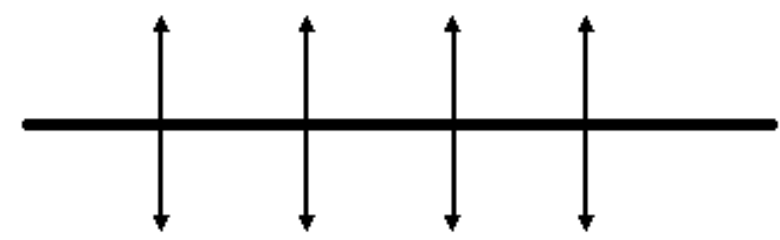

b)

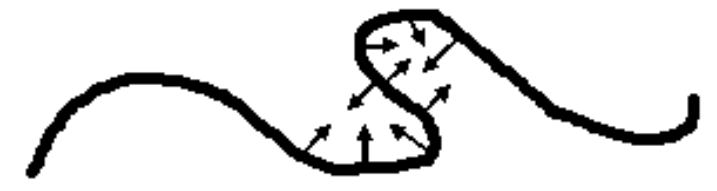

Figure 10 This figure represents the diffusion of solvents from two ink entries: (a) from a straight line, (b) inside the loops of a curved line. The solvent concentration will be significantly larger in $1 \mathrm{~cm}$ of (b) compared to $1 \mathrm{~cm}$ of (a).

The three categories of factors (ink composition, paper type and storage conditions) must be taken into account in any attempt to model NA by AA. Given the aging of a specific ink composition on a certain type of paper substrate stored in controlled conditions, the modelling could provide a good simulation, especially for solvents. But reproducing environmental conditions with all variables identical to real storage conditions of a questioned document might prove to be too complex in most cases. 


\section{Conclusion}

Artificial aging of ink on documents, carried out to accelerate the processes, is known to be used for three main reasons: hiding a backdating fraud by making the document look older than it really is [Stewart, 1982], studying the natural aging of ink by simulating different environmental conditions in a controlled way [Weyermann, 2005; Weyermann et al., 2006], dating an ink by provoking aging in order to calculate a small portion of aging curve [Aginsky, 1996; Brunelle, 1998].

The modelling of natural aging of dyes and solvents from ballpoint inks, however, proved to be very complex, because of the number of factors playing a role in the aging processes, such as the initial ink composition, the paper substrate and the storage conditions. Each of these groups of factors can be equally varied and is generally unknown in case investigations. These factors must be taken into account, however, for any attempt to compare artificial aging to natural aging. No model can be generalised to all inks stored under different conditions and on different papers.

\section{Acknowledgements}

The authors would like to acknowledge the assistance of Alfons Hester and wish to thank Dr. Eberhard Pitt and Dr. Georg Lasnitschka from the I. Physical Institute of the Justus Liebig University Giessen for their help and for lending of optical material which proved useful for this work.

\section{References}

> Aginsky, V.N. [1993]. Some New Ideas for Dating Ballpoint Inks- A Feasibility Study. Journal of Forensic Sciences, Vol.38, No. 5, pp. 1134-1150.

> Aginsky, V. N. [1996]. Accelerated Aging - Its Use in Methods for Dating Ink", International Journal of Forensic Document Examiners, Vol. 2, No. 3, pp. 179-181. 
> Aginsky, VN. [1998]. Measuring Ink Extractability as a Function of Age - Why the Relative Ageing Approach Is Unreliable And Why It Is More Correct to Measure Ink Volatile Components than Dyes. International Journal of Forensic Document Examiners, Vol. 4, No. 3, pp. 214-230.

> Andermann, T.; and Neri, R. [1998]. Solvent Extraction Techniques - Possibilities For Dating Ball Point Pen Inks. Journal of Forensic Sciences, Vol. 4, No. 3, pp. 231-239.

> Brunelle, R.L.; and Cantu, A.A. [1987]. A Critical Evaluation of Current Ink Dating Techniques. Journal of Forensic Science, Vol.32, No. 6, pp. 1522-1536.

> Brunelle, R.L.; and Lee, H. [1992]. Ink Dating- The State of the Art. Journal of Forensic Sciences, Vol. 37, pp. 113-124.

> Brunelle, R. L. [1998]. Technical Report with Case Studies on the Accelerated Aging of Ball-Point Inks. International Journal of Forensic Document Examiners, Vol. 4, No. 3, pp. 240-254.

$>$ Cantu, A. A.; and Prough R. S. [1987]. On the Relative Aging of Ink - The Solvent Extraction Technique. Journal of Forensic Sciences, Vol. 32, No. 5, pp. 1151-1174.

> Cantu, A. A. [1988]. Comments on the Accelerated Aging of Ink. Journal of Forensic Sciences, Vol. 33, No. 3, pp. 744-750.

> Cantu, A. A. [1995]. A Sketch of Analytical Methods for Document Dating Part I. The Static Approach: Determining Age Independent Analytical Profiles. International Journal of Forensic Documents Examiners, Vol. 1, No. 1, pp. 40-51

$>$ Cantu, A.A. [1996]. A Sketch of Analytical Methods for Document Dating Part II. The Dynamic Approach: Determining Age Dependent Analytical Profiles. International Journal of Forensic Documents Examiners, Vol. 2, No.3, pp.192-208.

> Chaurand, P.; Luetzenkirchen, F.; and Spengler, B. [1999] „Peptide and Protein Identification by Matrix Assisted Laser Desorption Ionization (MALDI) and MALDI-Post-Source Decay Time-of-Flight Mass Spectrometry“ Journal of the American Society for Mass Spectrometry, Vol. 10, pp. 91-103.

> Grim, D. M.; Siegel, J.; and Allison, J. [2002]. Evaluation of Laser Desorption Mass Spectrometric and UV Accelerated Aging Dyes on Paper as Tools for the Evaluation of a Questioned Document. Journal of Forensic Sciences, Vol. 47, No. 6, pp. 1265-1273.

> Hicks Champod, T.; Khanmy, A.; and Margot, P. [1995]. Ink Ageing: Perspectives on Standardization. Advances in Forensic Sciences 3, Forensic Criminalistics 1, Proceedings of the 13th Meeting of the 
International Association of Forensic Sciences, Düsseldorf, Germany 1993, Jacob B., Bonte W., Huckenbeck W. and Pieper P. Editors, Verlag Dr. Köster, Berlin, pp. 304-309.

> Jahns, K. [2004]. Altersbestimmung von Schreibmitteln durch chemische Analyseverfahren. Mannheimer Hefte für Schriftvergleichung, Peter E. Baier, Universität Mannheim, Schmidt / Römhild, 29. Jahrgang, $3 / 04$.

> Klessinger, M.; Michl, J. [1989]. Lichtabsorption und Photochemie organischer Moleküle. Martin Klessinger, VCH.

$>$ Lyter, A. H. [1994]. Relative Aging of Ball Pen Ink: Natural Aging vs. Artificial Aging. American Academy of Forensic Sciences Meeting, San Antonio, TX.

> Margot, P.; Hicks Champod, T.; and Khanmy, A. [1995]. Commentary. International Journal of Document Examiners, Vol. 1, No. 1, p. 4.

$>\quad$ Stewart, L. F. [1982]. Artificial Aging of Documents. Journal of Forensic Sciences, Vol. 27, No. 2, pp. 450453.

> Steward, L.F.; and Guertin, S. [1991]. Current Status of Ink Age Determination. International Criminal Police Review, 1991 (March-April), pp. 9-13.

> Stewart, L. F.; and Fortunato, S. L. [1996]. Distinguishing Between Relative Ink Age Determinations and the Accelerated Aging Techniques. International Journal of Forensic Document Examiners, Vol. 2, No. 1, pp. 10-15.

$>$ Weyermann C. Mass Spectrometric Investigation of The Ageing Processes of Ballpoint Ink For the Examination of Questioned Documents. Phd Thesis, Justus-Liebig-Universität Giessen, Germany, 2005. http://geb.uni-giessen.de/geb/volltexte/2006/3044/.

$>\quad$ Weyermann, C.; Kirsch, D.; Costa Vera, C.; and Spengler, B. [2006]. Forensic Investigation of Aging and Degradation of Ballpoint Dyes on Paper by LDI- and MALDI-MS Analysis. Journal of the American Society for Mass Spectrometry, Vol. 17, pp. 297-306.

> Weyermann, C.; Marquis, R.; Mazzella, W.; and Spengler, B. [2007]. Laser Desorption Ionization Mass Spectrometry and High Performance Thin Layer Chromatography Analyses of Blue Ballpoint Pen Inks. Journal of Forensic Sciences, Vol. 52, No. 1, pp. 216 - 220.

> Weyermann, C.; Kirsch, D.; Costa Vera, C.; and Spengler, B. [2007b]. A Study of The Drying of Ballpoint Pen Ink on Paper by GC/MS. Forensic Science International, Vol.168, No. 2-3, pp. 119-127. 
> Weyermann, C.; Schiffer, B.; and Margot, P. [2007c]. A logical framework to ballpoint ink dating interpretation. Science \& Justice, accepted October 2007. 